\title{
Infraestructuras urbanas sociotécnicas. Vender o no vender la ETB - Empresa de Telecomunicaciones de Bogotá
}

\author{
Infraestruturas urbanas sociotécnicas. Vender ou não vender \\ a ETB - Empresa de Telecomunicaciones de Bogotá \\ Socio-technical urban infrastructure. To sell or not to sell the \\ ETB - Empresa de Telecomunicaciones de Bogotá
}

Angie Carolina Torres Ruiz

Politóloga, Universidad de Los Andes, Bogotá, magíster en Teología, Pontificia Universidad Javeriana, Bogotá, investigadora de la Maestría en Gestión Urbana de la Universidad Piloto de Colombia, Bogotá, Cundinamarca - Colombia, e-mail:

carolina.angie@gmail.com

\section{Resumen}

Desde el campo de los estudios urbanos sociotécnicos, el texto analiza la controversia "vender o no vender la Empresa de Telecomunicaciones de Bogotá" (ETB), una empresa pública de la capital colombiana. La primera sección reseña el surgimiento, desarrollo y potencial crítico de dicho campo. La segunda sección expone el estudio de caso: el primer apartado presenta la ETB y su carácter sociotécnico; el segundo explora algunas controversias sucedidas en la interacción ETB-ciudad y contextualiza la controversia analizada; el tercero expone el diseño metodológico empleado que incluyó: i) conformación de un corpus de prensa escrita sobre la controversia "vender o no vender la ETB" sucedida en el año 2011, ii) adaptación de las categorías analíticas del protocolo de investigación $\mathrm{SCOT}^{1}$; y iii) aplicación del análisis de contenido al corpus textual con soporte en el software ATLAS/ti (versión 7). El cuarto apartado expone los resultados del análisis que permitió identificar los actores y argumentos que dominaron el debate y el marco tecnológico o conjunto de conceptos empleados para discutir y resolver el dilema "vender o no vender": por un lado, el conjunto "mercado de telecomunicaciones" y por otro, el conjunto "patrimonio público de la ciudad". La tercera sección de consideraciones finales critica la polarización que sustenta el dilema "vender o no vender", pues bloquea la comprensión de la interacción sociotécnica ETB-ciudad y el desarrollo de sus potencialidades.

Palabras-clave: Estudios urbanos sociotécnicos. Infraestructuras urbanas sociotécnicas, Empresa de Telecomunicaciones Bogotá.

\section{Resumo}

A partir do campo dos estudos urbanos sociotécnicos, aqui é analisada a controvérsia "vender ou não vender a Empresa de Telecomunicações de Bogotá" (ETB), uma empresa de telecomunicações pública da capital

\footnotetext{
1 Por sus siglas en inglés: Social Constructivism of Technology.
} 
colombiana. A primeira seção analisa o potencial de desenvolvimento, emergência e potencial crítico desse campo. A segunda seção apresenta o estudo de caso subdividido em quatro partes. A primeira abordagem expõe a ETB como uma entidade e comenta seu perfil sociotécnico; a segunda explora a polêmica envolvendo a interação entre a relação "ETB-cidade" e sua contextualização baseada na análise de controvérsia; a terceira abordagem descreve o desenho metodológico empregado que incluiu: i) desenvolvimento de um corpus de manchetes de jornais sobre a polêmica "vender ou não vender a ETB", que teve lugar em 2011, ii) adaptação das categorias analíticas seguindo o protocolo de pesquisa $\mathrm{SCOT}^{2}$; e iii) aplicação do corpus baseado em análise de conteúdo com suporte no programa de computação ATLAS/ti (versão 7). A quarta abordagem apresenta a análise que permitiu identificar os atores e argumentos predominantes sobre o debate e a estrutura tecnológica ou conjunto de conceitos utilizados para discutir e resolver o dilema "vender ou não vender": de um lado, o conjunto "mercado de telecomunicações", e, por outro lado, o conjunto "patrimônio público da cidade". A terceira seção sobre considerações finais criticou a ênfase dada à polarização que sustenta o dilema "vender ou não vender", a qual bloqueia a compreensão da interação sociotécnica dentro da interação "ETB-cidade" e o desenvolvimento do seu potencial.

Palavras-chave: Estudos sociotécnicos urbanos. Infraestrutura urbana sociotécnica. Empresa de Telecomunicações de Bogotá.

\section{Abstract}

From the field of urban studies here is analyzed the socio-technical controversy "to sell or not to sell Bogotá Telecommunications Enterprise" (ETB), a Colombian public telecommunication company. The first section reviews the emergence, development and critical potential of this field. The second section presents the case study sub-divided into four parts. The first approach exposes the ETB as an entity and its socio-technical profile; the second explores the controversy emerged involving the interaction between the relationship "ETBcity" and the contextualization based upon the controversy analysis; the third approach describes the design methodology employed which included: i) developed of a corpus of newspapers headlines on the controversy "to sell or not to sell the ETB" that took place in 2011; ii) adaptation of the analytical categories to the SCOT research protocol ${ }^{3}$ and; iii) application of content analysis to the corpus of news supported by the $s \neg$ oftware ATLAS/ti (version 7). At last, the fourth approach exposes the analysis which identified the predominant actors and arguments place on the debate and the technological frameworks or set of concepts used to discuss and resolve the dilemma "to sell or not to sell": on one side, the set denominated "telecommunications market", and, on the other side, the set denominated "the city's public patrimony". And, the third section regarding final considerations criticizes the emphasis given to the polarization set based upon the dilemma "to sell or not to sell", which is blocking the understanding of the socio-technical interaction within the relationship between "ETB-city" and overcrowding the development of their possible potential.

Keywords: Socio-technical urban studies. Socio-technical urban infrastructure. Bogotá Telecommunications Enterprise.

\section{La emergencia de los estudios urbanos sociotécnicos}

El origen de los estudios urbanos sociotécnicos se remonta al debate en torno a la construcción social del conocimiento científico y al estudio de sus expresiones materiales y simbólicas. En la década de los años sesenta del siglo pasado, la introducción de la variable "contexto" al análisis del desarrollo de la ciencia fue ampliamente reconocida. Esto significó la caída de la visión lineal, acumulativa y neutral del conocimiento científico impulsada por

2 Por sua sigla em Inglês: Social Constructivism of Technology.

3 For its acronym in English: Social Constructivism of Technology. 
el Círculo de Viena desde los años veinte (CARNAP; HANS; NEURATH, 2002). Entre el Círculo de Viena y el giro de los años sesenta, uno de los trabajos más influyentes fue el adelantado por Robert K. Merton, quien consagró el estudio del "ethos científico moderno" poniendo en evidencia que "[...] los científicos se han visto obligados a tomar conciencia de sí mismos, como elementos que forman parte de la sociedad y que tienen obligaciones e intereses" (MERTON, 1977, p. 355).

Otro hito importante fue el Coloquio Internacional de Filosofía de la Ciencia realizado en Londres en 1965. Éste recogió importantes discusiones entre las que sobresalió la sostenida entre Thomas Kuhn y Karl Popper en torno al progreso del conocimiento científico. Entonces, Kuhn afirmaba que el progreso se daba en la forma de revoluciones científicas, en las que la "ciencia extraordinaria" interrumpía el curso de la "ciencia normal" derribando las teoría insatisfactorias (KUHN, 2004). Por su parte, Popper, quien definía la labor científica como la búsqueda aproximativa y permanente de la verdad, afirmaba que el progreso del conocimiento científico se daba por el continuo proceso de falsación de las teorías científicas, es decir, por el testeo empírico-crítico de sus hipótesis, propiciando así la construcción de teorías cada vez más satisfactorias (POPPER, 1977).

En general, el ambiente de debate de los años sesenta estuvo animado por el estudio del carácter contextual e histórico del conocimiento científico y por la revisión crítica del trabajo científico delante de los desafíos explicativos e interpretativos de las teorías. En ese panorama, Kuhn advertía que "considerar la historia como algo más que un depósito de anécdotas o cronología, podía producir una transformación decisiva de la imagen que tenemos (actualmente) de la ciencia" (KUHN, 2004. p. 20). Popper, a su vez, señalaba que "siempre será asunto a resolver por una convención o una decisión el de a qué cosa hemos de llamar una 'ciencia' o el de a qué hemos de calificar de 'científico'” (POPPER, 1977, p. 51) pues, la ciencia, "no es el producto mágico de lo dado, los datos, las observaciones. No es un evangelio de verdad. Es el resultado de nuestros propios esfuerzos y errores" (POPPER, 1985, p. 300).
La productividad del clima de debate activado de manera significativa por la propuesta sociológica mertoniana y las propuestas epistemológicas de Kuhn y Popper es observable en el surgimiento de múltiples escuelas y programas de investigación, incluyendo aquellos que subsidiaron el surgimiento de los estudios urbanos sociotécnicos: el Programa Fuerte de Edimburgo y el Programa Empírico del Relativismo; la Sociología de la Tecnología y la escuela de Estudios de Ciencia y Tecnología; el programa de investigación de la Teoría del Actor-Red y el programa del Constructivismo Social de Tecnología.

\section{De la sociología de la ciencia a los estudios urbanos sociotécnicos}

Durante los años 70 y 80, dos programas de investigación fueron fundamentales para el posicionamiento de la reconstrucción histórica del conocimiento científico como trabajo epistemológico y empírico. Por una parte, la escuela del Programa Fuerte de Edimburgo, liderada por Barnes (1974) y Bloor (1976), profundizó el giro historicista en los años setenta. El Programa radicalizó el rechazo al positivismo racionalista desde una postura relativista (PÉREZ SEDEÑO, 2000) y se opuso a la "debilidad" del programa mertoniano por su carácter normativo y su autolimitación en las fronteras de la sociología (BARNES, 1974). Mediante la reconstrucción histórica del conocimiento científico, el Programa se propuso demostrar que éste es un producto cultural entre tantos otros, resultado de procesos sociales de disputa y validación.

Por otra parte, en los años ochenta, el Programa Empírico del Relativismo (EPOR ${ }^{4}$ ), liderado por Collins y Pinch (1982), profundizó la fundamentación empírica del relativismo. Mediante la reconstrucción de controversias científicas y artefactos técnicos, se propuso demostrar cómo los factores determinantes de las controversias, "lejos de basarse en procedimientos lógico-experimentales indiscutibles, son 'factores sociales' como el poder, la retórica y otros [...]" (LAMO DE ESPINOSA, 1993, p. 23). Mientras el Programa Fuerte promovió la reconstrucción histórica del conocimiento científico

\footnotetext{
4 Por sus siglas en Inglés: Empirical Program of Relativism.
} 
con un énfasis epistemológico, el EPOR promovió la reconstrucción de controversias científicas específicas con un énfasis empírico.

A partir de la línea de investigación empírica del EPOR surgió la Sociología de la Tecnología. Esta sociología rechazó tanto el privilegio de los factores sociales (determinismo social) como el privilegio de los factores tecnológicos (determinismo científico) para explicar los fenómenos técnico-científicos; propuso entonces una nueva comprensión de la relación entre tecnología y sociedad a través del proceso denominado coproducción. Tal proceso sería observable en los grandes proyectos tecnológicos y acontecimientos sociotécnicos que tienen "como resultado una nueva distribución de los elementos: cuestiones sociales que pasan a etiquetarse como fundamentalmente técnicas o científicas y, viceversa, problemas de orden técnico y científico que adquieren el rango de cuestiones sociales" (AIBAR, 1996, p. 163).

La escuela más representativa de la Sociología de la Tecnología es la de Estudios de Ciencia y Tecnología (STS ${ }^{5}$ ) liderada desde los años noventa por Latour (1992). La STS dio origen a la Teoría del Actor-Red $\left(\mathrm{ANT}^{6}\right)$ con foco en el estudio de las relaciones sociotécnicas, y al Constructivismo Social de Tecnología ( $\mathrm{SCOT}^{7}$ ) con foco en el estudio de los artefactos y las tecnologías (AIBAR, 2008). Estos dos programas de investigación constituyen, según Aibar (1996, p. 165), los principales modelos analíticos para el estudio de la relación entre cambio social e innovación tecnológica.

El estudio de la construcción social del conocimiento científico promovido por el EPOR y el estudio de las innovaciones y controversias tecnológicas promovido por el programa SCOT, recibieron un impulso metodológico importante gracias al trabajo de Pinch y Bijker (1984). Estos autores proyectaron el modelo de análisis SCOT a la deconstrucción de artefactos tecnológicos específicos mediante la aplicación de un protocolo de investigación que permitiría "abrir la caja negra" de su proceso de construcción, es decir, revelar los procesos de interpretación y negociación de los distintos grupos sociales involucrados en su origen y desarrollo ${ }^{8}$. El protocolo consiste en identificar:

[...] primero, la existencia de grupos sociales que presentan visiones particulares de acuerdo a su interés. Segundo, el fenómeno de flexibilidad interpretativa con relación a problemas y soluciones, es decir, la existencia misma de problemas y de soluciones es relativa al grupo social. Tercero, existen mecanismos sociales que permiten el cierre de las controversias iniciadas, que a veces puede lograrse por demostración de la ventaja técnica en sí, o por retórica y/o mediante propaganda, entre muchos otros. Cuarto, existe un marco tecnológico o conjunto de conceptos y técnicas empleados por una comunidad para la solución de problemas (BIJKER, 1997, p. 11 apud VALDERRAMA, 2004, p. 219).

Según Farías (2011), la implementación de los modelos ANT y SCOT cobra especial relevancia en el campo de los estudios urbanos a partir de las siguientes obras: Paris Ville Invisible (LATOUR, HERMANT, 1998); Cities: Reimagining the Urban (AMIN; THRIFT, 2002) y Splintering Urbanism: Networked Infrastructures, Technological Mobilities and the Urban Condition (GRAHAM, MARVIN, 2001). En este campo existiría un consenso en torno a la obra de Graham y Marvin (2001) como referente principal (FARÍAS, 2011, p. 15, 19), pues, recoge las investigaciones más relevantes y establece la "distinción entre las infraestructuras de la ciudad como ensamblajes sociotécnicos, y la ciudad como proceso sociotécnico resultante de la interacción de estos múltiples ensamblajes" (FARÍAS, 2009 apud FARÍAS, 2011, p. 16). Así, el análisis de la construcción social de la ciudad como artefacto tecnológico será una de las vertientes más prolíficas de los estudios urbanos, dedicada al análisis de los "grandes sistemas técnicos" (transporte, energía, agua, telecomunicaciones, etc.) y los fenómenos sociotécnicos de la vida urbana.

\footnotetext{
${ }^{5}$ Por sus siglas en Inglés: Science and Technology Studies.

${ }^{6}$ Por sus siglas en Inglés: Actor - Network Theory.

7 Por sus siglas en inglés: Social Constructivism of Technology.

8 El trabajo más recordado de estos investigadores giró en torno a la deconstrucción de la historia de la bicicleta, artefacto tecnológico cuyas sucesivas modificaciones en el uso social, el formato o diseño y las prestaciones técnicas expresaron controversias sociotécnicas complejas: técnica, estética, feminismo, lucha de clases, prestigio social, etc. (PINCH; BIJKER, 1984).
} 
Este recorrido por algunos antecedentes de los estudios urbanos sociotécnicos y por sus programas y escuelas más relevantes permite reconocer que sus opciones teóricas y metodológicas son portadoras de un germen crítico sedimentado: el compromiso de revelar "la caja negra" de los fenómenos y objetos investigados. No solo en el contexto urbano, son variados los artefactos y fenómenos "naturalizados", sin memoria de su conflictivo proceso de construcción; por tanto, son múltiples las oportunidades de investigación crítica para un campo "obsesionado" con la tarea de desnaturalizar sus objetos de interés y evidenciar las relaciones, los actores, los intereses, las disputas y negociaciones que los originan y modifican. En este marco y con el interés de evidenciar esas variables, se presenta el análisis de un periodo de controversia en torno a la posible venta de una infraestructura urbana: la Empresa de Telecomunicaciones de Bogotá, en adelante ETB.

\section{Vender o no vender la Empresa de Telecomunicaciones de Bogotá}

\section{La ETB, infraestructura urbana sociotécnica}

Para la aproximación al carácter sociotécnico de la ETB se propone, a continuación, la lectura de algunos eventos de su historia. Antes, es pertinente retomar el llamado a considerar "la historia como algo más que un depósito de anécdotas o cronología" (KUHN, 2004, p. 20) pues, también con respecto a ésta es posible transformar la imagen que tenemos. Con esa intención, se listan a continuación los eventos reseñados en la sección "nuestra historia" del portal WEB de la ETB (http://www.etb.com.co ${ }^{9}$ ) conservando el orden cronológico allí expuesto. Si bien el formato de "listado" no es el más adecuado para aplicar el consejo kuhniano, sí es práctico para alcanzar tres propósitos adicionales: primero, identificar la presencia simultánea de factores tecnológicos y sociales; segundo, identificar relaciones de coproducción sociotécnica y, tercero, identificar aquellos eventos que podrían haber representado coyunturas conflictivas en la historia de la ETB.
- La ETB nació el 28 de agosto de 1884 como Compañía Colombiana de Teléfonos.

- En 1900, cuando había cien líneas instaladas, un incendio destruyó la central.

- En 1906 reanudó la prestación del servicio de telefonía como The Bogota Telephone Company.

- En 1932, ante las continuas protestas por las alzas en las tarifas, el Concejo municipal decidió que el municipio debía adquirir la compañía y la administración de la ciudad asumió el control del servicio, aunque la concesión otorgada para la explotación del servicio a The Bogota Telephone Company era por 50 años.

- En 1940, mediante el acuerdo 79 del Concejo, se constituyó la Empresa de Teléfonos de Bogotá, una entidad descentralizada y de propiedad ciento por ciento de la ciudad.

- En 1938 comenzó la modernización y se consolidó una década después cuando desaparecieron las operadoras y se abrió camino la automatización total, permitiendo la expansión del servicio a las casas de los bogotanos, pues hasta entonces tenía un carácter más empresarial.

- En 1961 entraron en funcionamiento centrales en Usaquén, Bosa, Suba y Centro Nariño ${ }^{10}$.

- A finales de los años 70 los usuarios eran cerca de 400,000 y hacia 1985 eran 710,000.

- Después de 52 años con el mismo nombre, en 1992 pasó a ser la Empresa de Telecomunicaciones de Bogotá por la diversificación de sus actividades.

- El Decreto Ley 1900 de 1990 y la Ley de Servicios Públicos de 1994 abrieron las puertas a la competencia en Colombia y en 1996 aparecieron otras empresas de telecomunicaciones.

- En 1997 el Concejo autorizó la conversión de la ETB en una sociedad por acciones, siendo su socio mayoritario el Distrito Capital.

- En 1998 el Concejo aprobó la venta de acciones a un socio estratégico internacional. Dicha venta no se dio, pero le dejó a la Empresa

\footnotetext{
9 Accedido en 30 agosto 2011 y enero 2012.

${ }^{10}$ Usaquén, Bosa, Suba y Centro Nariño son algunas de las localidades o zonas administrativas en las que se divide actualmente la ciudad de Bogotá.
} 
cerca de 1.000 accionistas entre empleados, ex empleados y pensionados. Así, se convirtió en sociedad por acciones de capital mixto.

- En 1998 el Ministerio de Comunicaciones le extendió una licencia para operar el servicio de larga distancia nacional e internacional.

- En el año 2000, la Compañía inició la operación de la red de datos a través de su marca Data Mundo, y su nodo de Internet.

- En 2001, la ETB creó la Oficina de Defensoría del Cliente y puso en marcha un Plan de Transformación para enfocar la Empresa hacia los clientes.

- En 2002, comenzó la modernización de teléfonos públicos de Bogotá que incluyó el cambio de teléfonos públicos que funcionaban con monedas por aparatos que operaban con tarjetas prepago.

- En 2003, el Ministerio de Comunicaciones le otorgó a la ETB, en conjunto con Empresas Públicas de Medellín (EPM), la licencia de PCS, lo que le dio la posibilidad de ingresar al mercado de la telefonía móvil.

- En 2003, la Compañía realizó un proceso de democratización accionaria que le permitió obtener recursos por 245 mil millones y vinculó a 61.313 colombianos como inversionistas.

- En agosto de 2003, la ETB incursionó en el negocio de los centros de contacto telefónico a través de una alianza comercial con Publicar S.A. y creó la compañía Contact Center Américas (Portal WEB, ETB).

El listado de eventos - extraído del brochure empresarial que comunica información significativa y positiva para un público amplio y no constituye, por tanto, una versión crítica de la historia institucional - sugiere un largo expediente de procesos sociales y tecnológicos no exento de conflictos. El denominado proceso de coproducción entre "factores tecnológicos y sociales" es observable en la ETB, aun cuando no represente lo que la Sociología de la Tecnología denomina un "gran proyecto tecnológico" o un "gran evento sociotécnico". Esta infraestructura constituye un microescenario de procesos sociotécnicos que también revela cómo "cuestiones que eran consideradas asuntos sociales han pasado a etiquetarse como técnicas o científicas, y problemas que eran considerados de orden técnico y científico han adquirido el rango de cuestiones sociales" (AIBAR, 1996, p. 163). Vale la pena identificar a continuación algunos ejemplos.

El asunto de las tarifas por concepto de servicio fue considerado un problema predominantemente político en los años treinta; actualmente es considerado un problema predominantemente técnico. En otro caso, la expansión del servicio de telefonía al sector residencial en los años treinta hizo parte de un proyecto de modernización de la empresa y la ciudad; actualmente, el rol de la ETB en la expansión de los servicios de telecomunicaciones es considerado un asunto técnico-empresarial en el ámbito del mercado, desligado de cualquier proyecto de ciudad ${ }^{11}$. Otro ejemplo es la modificación de la relación entre implementación de tecnologías y hábitos de consumo; hasta finales de los años noventa, los cambios de tecnología incorporados por la ETB obligaron a los usuarios a modificar sus hábitos de consumo en el sector de las comunicaciones como en el caso de la modificación del sistema de pago del servicio de teléfonos públicos en monedas por el sistema de tarjetas prepago -; finalizados los noventa, los hábitos de consumo de los usuarios en interacción con nuevas tecnologías ofertadas por múltiples actores comenzaron a superar las posibilidades de oferta de la ETB y a demandarle la incorporación de nuevas tecnologías.

Frente a estas coproducciones sociotécnicas, intentar trazar los límites exactos entre lo exclusivamente técnico y lo exclusivamente social o intentar explicarlas a partir de una lógica jerárquica resulta

\footnotetext{
${ }^{11}$ Vale la pena mencionar que de las últimas tres administraciones que ha tenido la ciudad (2004-2007; 2008-2011; 2012-2016), todas ellas de izquierda, dos han rechazado cualquier posibilidad de venta de la ETB. El titular de la administración 2008-2011, Samuel Moreno, promovió la venta de la ETB, pero, tras la sanción disciplinaria que le fue impuesta por omisión de sus responsabilidades de control y vigilancia en el desarrollo de obras públicas de la ciudad, la alcaldesa encargada que lo sucedió se opuso a la propuesta de venta radicada por su copartidario. Todavía, ninguna de las administraciones ha logrado generar consensos en torno al rol que podría cumplir la ETB en el proyecto de ciudad, más allá de reivindicar la importancia (abstracta) de las tecnologías de la información y las comunicaciones y la importancia de los recursos que genera para la inversión social del Distrito Capital
} 
una tarea difícil y probablemente improductiva ${ }^{12}$. La permanencia y las modificaciones de la ETB, al igual que en cualquier otra infraestructura urbana, se dan gracias a la constante interacción entre medios técnicos y sociales (BIJKER, 1993 apud AIBAR, 1996, p. 161). Esa interacción hizo posible la reactivación de la central después del incendio del año 1900, cuando la ciudad alcanzaba sus primeras cien líneas telefónicas; y es esa interacción la que podría reconfigurar la disposición de los factores tecnológicos y sociales para resolver el dilema quinceañe$\mathrm{ro}^{13}$ en torno a su posible venta.

\section{Controversias e interacción ETB-ciudad}

En los eventos previamente listados, además de dinámicas de coproducción sociotécnica, es posible identificar momentos que debieron ser altamente conflictivos y en los que la toma de decisiones modificó o podía modificar el curso de interacción ETB-ciudad. Por ejemplo, el periodo de protestas por las tarifas que terminó en la cancelación de la concesión privada y la municipalización de la empresa en 1932, en medio de la inauguración del periodo de gobiernos liberales que lideraron procesos de industrialización, urbanización y modernización (JARAMILLO URIBE, 1987). Otro ejemplo: el periodo de conversión de la ETB de una empresa pública a una sociedad por acciones de capital mixto en los noventa, en medio de la implementación de políticas de ajuste estructural, apertura económica y privatización. En este último contexto comienzan la búsqueda de socio estratégico y los intentos de venta que, además, son presionados por las dinámicas del mercado global de las telecomunicaciones que demanda altas inversiones para la actualización tecnológica y la competencia con grandes corporaciones.
Los periodos de controversia son "lugar" privilegiado para el análisis de la construcción social de la realidad, es decir, para el análisis de su desarrollo histórico y contextual. El Programa Empírico del Relativismo reconstruyó controversias científicas para demostrar el carácter social de la construcción del conocimiento científico (COLLINS; PINCH, 1982); la Sociología de la Tecnología reconstruyó grandes proyectos tecnológicos y acontecimientos sociotécnicos para demostrar que son resultado de procesos de coproducción (LATOUR, 1992); con similar intención, la Escuela de Estudios de Ciencia y Tecnología reconstruyó relaciones sociotécnicas, artefactos y tecnologías (AIBAR, 2008). La reconstrucción crítica de las controversias permite dar cuenta del contexto y corrige las lecturas esencialistas o transistóricas al visibilizar los actores, recursos, estrategias e intereses en disputa.

En este estudio de caso, se propone la reconstrucción crítica de una controversia específica en la trayectoria de una infraestructura urbana sociotécnica. Tal tipo de controversia es comprendida en este texto como un periodo específico de conflicto que implica la toma de decisiones capaces de modificar la forma vigente de interacción infraestructura-ciudad. La reconstrucción crítica de este tipo de controversias no consiste pues en evaluar la decisión o sus impactos, sino en identificar los actores y argumentos que incidieron en la toma de decisiones específicas de las que depende la vigencia o modificación del modo de relación entre una infraestructura sociotécnica y una ciudad.

Aquí se pretende "abrir la caja negra" de la controversia en torno a la posible venta de la ETB, propuesta discutida entre febrero y julio del año 2011. En febrero la controversia de la venta fue activada gracias al debate convocado por la Comisión de Hacienda del Concejo de Bogotá tras el fracaso de la búsqueda de socio estratégico en el 2010; allí

\footnotetext{
${ }^{12}$ Puede el lector hacer el intento y dictaminar si los factores determinantes de cada evento listado son de tipo exclusivamente tecnológico o exclusivamente social y descubrir así una posible inclinación por el determinismo de uno u otro tipo; en cualquier caso, la productividad del ejercicio dependerá de la disposición a revelar el modelo de análisis y a discutir el dictamen.

${ }^{13}$ En 1997 se empezó a ambientar la discusión sobre la venta de la ETB en el marco de las reformas estructurales y sus medidas de privatización; en 1998 se buscó, por primera vez y sin éxito, la venta de acciones a un socio estratégico internacional. A la fecha, están por cumplirse los primeros quince años del dilema. Por "dilema quinceañero" también se hace referencia a "dilema adolescente", entendiendo por dilema el recurso retórico que obliga a elegir entre dos opciones excluyentes entre sí, y por adolescente, el participio activo del verbo latino adolescere: "el que está creciendo".
} 
el entonces presidente de la compañía, Fernando Carrizosa, sostuvo: "hay que venderla, porque, definitivamente, esa es la mejor opción"14. Entre febrero y julio, los argumentos a favor y en contra del proyecto de venta circularon en distintos escenarios y era el Concejo de Bogotá, órgano de control político de la ciudad, el responsable de aprobar o no el proyecto de venta. En julio circuló la idea de promover una consulta popular para que los ciudadanos decidieran directamente si la ciudad debía o no vender ese activo y, el mismo mes, la controversia fue cerrada por los concejales, quienes rechazaron por unanimidad el Proyecto de Acuerdo 172 de 2011 que promovía la venta del $88,4 \%$ de las acciones ${ }^{15}$.

Para abrir la caja negra de la controversia: "this side up"

Abrir la "caja negra" de la controversia estudiada implica identificar los actores interesados y sus argumentos, particularmente aquellos dominantes que determinaron su cierre o transformación. Dos de los "espacios" que registraron el desarrollo de la controversia fueron, por un lado, el espacio de control político del Concejo de Bogotá y, por otro, el espacio público de comunicación a través de los mass media. Entre éstos últimos, la selección de la prensa escrita como fuente para la identificación de los actores y argumentos ofrece cuatro ventajas: (1) el cubrimiento fue intenso y produjo un volumen importante de información; (2) registró tanto los debates formales que ocurrían en el Concejo de Bogotá, como los informales que ocurrían fuera de éste; (3) visibilizó una pluralidad de actores e intereses que no aparecen en los registros del debate formal; y (4) la exposición pública que otorgó a unos actores y argumentos específicos permite identificar aquellos que mantuvieron un carácter dominante en el debate. En general, la prensa es una institución que aborda los conflictos de las sociedades e influencia el proceso de distribución y posicionamiento de interpretaciones a través de mecanismos de visibilización, construcción y circulación informativa (BONILLA; GARCÍA RAYA, 1998). Por lo expuesto anteriormente, este análisis crítico optó por abrir "la caja negra" en el espacio público de comunicación y a partir del análisis de prensa escrita.

Los diarios seleccionados fueron "El Tiempo"16 y "El Espectador"17 por ser los de mayor circulación en Bogotá. Frente a la controversia estudiada, sus líneas editoriales se comportaron de forma diferente, mientras la línea editorial de El Tiempo apoyó abiertamente la propuesta de venta, la de El Espectador no tomó partido y realizó un cubrimiento más completo sobre las diferentes posiciones; aunque los dos diarios visibilizaron un abanico amplio de actores y argumentos. La identificación del universo de noticias, setenta y un (71) en total, fue realizada mediante búsqueda electrónica por palabra-clave empleando las etiquetas "venta de la ETB" y "venta ETB". El corpus textual está compuesto por treinta y seis textos (36) del diario "El Tiempo" y treinta y cinco (35) del diario "El Espectador" y reúne notas informativas y notas editoriales o de opinión. Como fue explicado previamente, el recorte temporal comprende el periodo entre febrero y julio de 2011.

Para la reconstrucción de la controversia fue aplicada la técnica de análisis cualitativo de contenido cuyo propósito es decodificar los mensajes conforme a categorías teóricas (BARDIN, 2011). En este caso, tales categorías fueron establecidas a partir de la adaptación de las categorías analíticas del protocolo SCOT, a saber: grupos sociales con visiones particulares; interpretaciones de los problemas y las soluciones; mecanismos de cierre de la

\footnotetext{
${ }^{14}$ Candente debate en el Concejo de Bogotá por venta de ETB, en El Tiempo, Bogotá, 7 de febrero de 2011.

${ }^{15}$ El otro 86,6\% de las acciones están a nombre de la ETB y el otro porcentaje pertenece a empresas públicas distritales: la Empresa de Acueducto y Alcantarillado de Bogotá (EAAB), al Fondo de Prestaciones Económicas, Cesantías y Pensiones (FONCEP), a la Lotería de Bogotá y al Instituto de Desarrollo Urbano (IDU). El otro porcentaje está en manos privadas.

${ }^{16}$ El Tiempo es el diario nacional de mayor tiraje en Colombia y es considerado de línea editorial oficialista. Es importante señalar que durante el periodo de revisión, la Organización Luis Carlos Sarmiento Angulo (OLSA), una de las dos organizaciones empresariales más poderosas del país, era propietaria del 33.37\% de la Casa Editorial El Tiempo, conglomerado de medios de comunicación del cual hace parte el mencionado diario, y, simultáneamente, el grupo empresarial hacía parte de la junta directiva de la ETB.

${ }^{17}$ El Espectador es el diario nacional más antiguo del país, su línea editorial es considerada de centro e independiente y tiene menor tiraje respecto a El Tiempo.
} 
controversia y marco tecnológico conformado por diversos elementos tales como teorías y conceptos, prácticas, estrategias y técnicas que definen tanto la controversia como las posibilidades de solución (BIJKER, 1997). Tal como fue explicado en la primera sección del documento, el protocolo SCOT es empleado para la reconstrucción crítica de artefactos y tecnologías, razón por la cual sus categorías fueron adaptadas para el ejercicio de análisis de contenido (Cuadro 1). Así, se entiende por "actores partícipes de la controversia" aquellos cuyas visiones particulares sobre la ETB y la controversia tienen exposición predominante en los registros analizados; se entiende por "problemas" y "soluciones" aquellos adjudicados por los actores partícipes de la controversia; se entiende por "argumentos de cierre de la controversia" aquellos que sustentaron la decisión tomada, y se entiende por "marco tecnológico" los conjuntos de conceptos empleados predominantemente en la trayectoria de la controversia.

\section{Vender o no vender, versión 2.011}

En la trayectoria de la controversia, los actores que tuvieron participación fueron numerosos y diversos (Cuadro 2).

Entre ese amplio abanico de actores, la prensa escrita visibilizó las interpretaciones de los más influyentes en el proceso de debate, aquellos que aparecieron con mayor frecuencia o aquellos que recibieron un mayor espacio para la exposición de sus argumentos. Así, la comprensión de los problemas y las soluciones posibles de la ETB fueron dominadas por un grupo reducido de actores y argumentos provenientes de la esfera del mercado y el sector público.

Con respecto a los problemas de la ETB, el texto de Proyecto de Acuerdo n. 172 de 2011 radicado en el Concejo de Bogotá para tramitar la venta señala que la ETB no cuenta con la "capacidad de inversión para proveer una oferta adecuada de servicios, tecnología, permanente innovación y desarrollo ni [...] competir de manera agresiva en el mercado de las telecomunicaciones". No obstante, el debate en torno a los problemas de la ETB superó las variables capacidad de inversión, oferta adecuada, tecnología e innovación. En el desarrollo de la controversia fue posible identificar un núcleo frente al cual existe un "consenso conflictivo" (MOUFFE, 2005) entre opositores y partidarios de la venta y otro núcleo que genera cuestionamientos, pues los problemas allí señalados aún son objeto de interpretación y disputa (Cuadro 3).

La controversia en torno a la venta o no venta comenzó centrada en el análisis de las condiciones financieras y los problemas de gerencia de la empresa; progresivamente fueron introducidos argumentos y análisis que enriquecieron la discusión sobre lo que significa la ETB como estructura sociotécnica de la ciudad, permitiendo así la ampliación del marco tecnológico de análisis y la multiplicación de las opciones. El panorama de las soluciones

Cuadro 1 - Adaptación de Protocolo de Investigación SCOT al caso ETB

\begin{tabular}{|c|c|}
\hline Protocolo de investigación SCOT & $\begin{array}{l}\text { Adaptación de categorías para el análisis } \\
\text { de la controversia "vender o no vender la ETB" }\end{array}$ \\
\hline $\begin{array}{l}1 \text { - Identificación de grupos sociales que presentan visiones particulares } \\
\text { de acuerdo a su interés. }\end{array}$ & $\begin{array}{l}\text { Actores partícipes de la controversia: actores que expresan visiones particulares } \\
\text { sobre la ETB y la controversia }\end{array}$ \\
\hline $\begin{array}{l}2 \text { - Identificación de flexibilidad interpretativa con relación a problemas y } \\
\text { soluciones según los grupos sociales. }\end{array}$ & $\begin{array}{l}\text { Problemas ETB: problemas adjudicados a la ETB por los actores partícipes de la } \\
\text { controversia } \\
\text { Soluciones ETB: soluciones propuestas por los actores partícipes de la controversia }\end{array}$ \\
\hline $\begin{array}{l}3 \text { - Identificación de mecanismos sociales que permiten el cierre de las } \\
\text { controversias iniciadas: ventaja técnica, retórica, propaganda, etc. }\end{array}$ & $\begin{array}{l}\text { Argumentos de cierre de la controversia: argumentos que sustentan la decisión de } \\
\text { frente a la controversia vender o no vender la ETB }\end{array}$ \\
\hline $\begin{array}{l}4 \text { - Identificación de marco tecnológico o conjunto de conceptos y técni- } \\
\text { cas empleados por una comunidad para la solución de problemas. }\end{array}$ & $\begin{array}{l}\text { Marco tecnológico: conjuntos de conceptos más relevantes en la trayectoria de la } \\
\text { controversia en torno al dilema vender o no vender la ETB }\end{array}$ \\
\hline
\end{tabular}

Fuente: Elaboración propia, con base en BIJKER, 1997, p. 11 apud VALDERRAMA, 2004, p. 219. 
Cuadro 2 - Actores en la controversia

\begin{tabular}{|c|c|}
\hline Agrupación de actores & Actores \\
\hline Actores del gobierno nacional & $\begin{array}{l}\text { Gobierno Nacional - Presidente de la República, Juan Manuel Santos; María Fernanda Campo, Ministra de Educación } \\
\text { (alcaldesa (e.) de la ciudad); Cristina Plazas, secretaria del Consejo de Ministros (designada como alcaldesa 'ad } \\
\text { hoc' para presentar el Proyecto de Acuerdo para la venta de acciones de la ETB); Diego Molano, Minisistro de las TIC; } \\
\text { Senador Jorge Robledo. }\end{array}$ \\
\hline Actores del gobierno distrital & $\begin{array}{l}\text { Alcalde Samuel Moreno; Beatriz Elena Arbeláez, Secretaria de Hacienda (Administración Moreno); Concejo de Bogotá; } \\
\text { Comisión de Hacienda del Concejo de Bogotá; Comisión de Gobierno del Concejo de Bogotá; Concejales a favor de la } \\
\text { venta (ej. Felipe Ríos); Concejales en contra de la venta (ej. Jaime Caicedo, Fernando Rojas, Álvaro Argote, Celio Nieves); } \\
\text { María Victoria Vargas, Presidenta del Concejo; ponentes Edward Árias (Partido Verde), Laureano García (PDA) y Andrés } \\
\text { Felipe Arbeláez (Movimiento Político Mira); Clara López Obregón, presidenta del PDA y alcaldesa encargada; Héctor } \\
\text { Zambrano, Secretario de Hacienda; Yuri Chillán, Secretario general del Distrito; Distrito e otras entidades distritales. }\end{array}$ \\
\hline $\begin{array}{l}\text { Partidos Políticos con curul en el Concejo } \\
\text { de Bogotá }\end{array}$ & $\begin{array}{l}\text { Cambio Radical; Partido Conservador; Movimiento Político Pacto; Partido Liberal; Partido Polo Democrático Alternativo; } \\
\text { Partido Verde Opción Centro; Movimiento Político Mira. }\end{array}$ \\
\hline Actores ETB & $\begin{array}{l}\text { Empresa de Telecomunicaciones de Bogotá (ETB); Fernando Carrizosa, presidente de la compañía; Junta Directiva; } \\
\text { Asamblea de Accionistas; accionistas; Sindicato de trabajadores de la ETB (Sintrateléfonos); Oscar Penagos Ortiz, } \\
\text { presidente del sindicato. }\end{array}$ \\
\hline Órganos e instancias de control & $\begin{array}{l}\text { Procuraduría General de la Nación; Superintendencia Financiera; Contraloría de Bogotá; Mario Solano, Contralor de } \\
\text { Bogotá; Red de Veedurías Ciudadanas. }\end{array}$ \\
\hline Órganos de la Rama judicial & Tribunal Administrativo de Cundinamarca; Juzgado 38 Administrativo del Circuito de Bogotá. \\
\hline Candidatos a la Alcaldía de Bogotá & $\begin{array}{l}\text { Gustavo Petro; Jaime Castro; Luis F. Rosas; Enrique Peñalosa (exalcalde); Carlos F. Galán; Gina Parody; Carlos } \\
\text { Guevara; David Luna; Jaime Castro (exalcalde y exconsituyente). }\end{array}$ \\
\hline Actores de otras ciudades & Alcaldía de Medellín; Empresas Públicas de Medellín (UNE-EMP). \\
\hline Mass Media & El Tiempo; Guillermo Santos Calderón, línea Editorial El Tiempo; El Espectador. \\
\hline Sociedad civil & Sociedad Colombiana de Ingenieros; Concejo Cómo Vamos. \\
\hline Otros actores & Mercado de telecomunicaciones; Bolsa de Valores de Colombia; la ciudad; los ciudadanos. \\
\hline Empresas del sector TIC & $\begin{array}{l}\text { Empresas del sector de telecomunicaciones que han expresado interés en la ETB: Telefónica (España), Telmex } \\
\text { (México), Oi (Brasil). }\end{array}$ \\
\hline Calificadoras de riesgo & Fitch Ratings; Moodys Investor Services. \\
\hline
\end{tabular}

Fuente: Elaboración propia, con base en el análisis de prensa (Anexos 1 y $2^{18}$ ).

planteadas por los actores que dominaron la controversia puede ser resumido en tres estrategias excluyentes entre sí: venta preventiva, fortalecimiento mediante socio estratégico y fortalecimiento público. Tales estrategias persiguen objetivos, medios y valores diferentes, no necesariamente excluyentes, e implican medidas y esfuerzos de complejidad diferenciada que fueron promovidos por actores específicos (Cuadro 4).
El inventario de los conceptos que dominaron el análisis de los problemas de la ETB y las soluciones posibles, así como su posterior clasificación (BARDIN, 2011), permitieron la identificación del marco tecnológico que orienta la comprensión de la controversia y las posibilidades de resolución del dilema vender o no vender a partir de dos conjuntos de conceptos: el conjunto mercado de telecomunicaciones y el conjunto empresa patrimonio público de la ciudad (Cuadro 5).

\footnotetext{
${ }^{18}$ Anexos 1 y 2 disponibles en: <https://dl.dropbox.com/u/74428475/Anexos\%201\%20y\%202.xlsx>.
} 
Cuadro 3 - Los problemas de la ETB

Problemas frente a los que hay consenso conflictivo

- Los problemas son producto de una cadena de decisiones equivocadas en la gerencia de la ETB.

- La gerencia ha sido deficiente, no ha logrado posicionar los productos de la ETB en el mercado y ha permitido la pérdida de liderazgo en el sector de Internet.

- Sus recursos son limitados para competir.

- No hay un plan claro de capitalización o desarrollo.

- La corrupción ha debilitado a la ETB.

- La ETB está rezagada en la oferta de servicios tecnológicos por no haber dado el salto a la operación de telefonía móvil ni al servicio de televisión por subscripción lo que redujo la diversificación y el empaquetamiento de servicios digitales.

- Los hábitos de consumo de los usuarios superan las posibilidades de oferta actual de la ETB.

- La fortaleza de la ETB está en el segmento de telefonía fija y ese es un segmento que tiende a disminuir su tamaño en el mercado local.

- La ETB no puede competir con las grandes compañías de las telecomunicaciones.

- La gerencia y la Junta Directiva propusieron la venta de la ETB anunciando que la empresa atravesaba una fuerte crisis, incidiendo en la estimación a la baja del posible precio de venta, establecido por debajo del valor de sus activos.

\section{Problemas frente a los que no hay consenso}

- La gerencia ha sido deficiente en la atracción de inversionistas (debe ceder el control, es imposible operar con lógica privada y pública).

- Los resultados financieros son sólidos, pero su rentabilidad es declinante:

- no genera los recursos necesarios para ofrecer los servicios que demanda el sector;

- el EBITDA demuestra pérdida progresiva de valor (pasó de $52.6 \%$ en 2004 a $49,9 \%$ en 2009 y al $51 \%$ en 2010 ;

- Ia tendencia en los ingresos de la ETB ha presentado una disminución promedio de 1,9\% durante las últimas cuatro vigencias;

- ha caído la utilidad neta de la ETB (\$185 mil millones en 2006 y \$121 mil millones en 2010);

- tiene una baja economía de escala que le impide tener tarifas competitivas;

- no optimiza costos y gastos;

- el precio de las acciones es inestable (por falta de solidez o por especulación);

- Ni la ETB ni el Distrito están en condiciones de invertir en su actualización ni en innovación.

- La ETB es víctima del manejo politiquero de la Administración Distrital y del Sindicato.

- La concentración del mercado en Bogotá dificulta su expansión.

- América Latina ha implementado un modelo eficiente de operación privada de las telecomunicaciones. Hay tres excepciones: Bogotá, Cali y Medellín; Bogotá fracasó.

- La postergación de la venta incide en la constante pérdida de valor de la empresa (hoy cuesta la mitad de lo que costaba hace 5 años).

- Aunque genera ingresos importantes, no es competitiva en el sector y no podrá resistir.

- Los activos de la empresa y cualquier tipo de inversión en ésta están en riesgo.

Fuente: Elaboración propia, con base en la revisión de prensa (Anexos 1 y 2).

Estos dos conjuntos categoriales configuran los discursos dominantes que obtuvieron mayor exposición pública en la prensa y que disputaron la controversia en torno a la posible venta. Por un lado está el discurso que comprende la ETB como una empresa del sector de telecomunicaciones cuyas decisiones deben ser formuladas y evaluadas en la esfera del mercado y, por otro, el discurso que comprende la ETB como empresa y patrimonio público de la ciudad de Bogotá, cuyas decisiones deben ser formuladas y evaluadas en la esfera de la política, con consideración de las realidades del mercado (Cuadro 6).

Cada uno de los discursos expresó, a su vez, una versión distinta del dilema "vender o no vender la
ETB". Las dos versiones del dilema implican la "salvación de la ETB", por un lado, mediante la estrategia de la "venta preventiva", y, por el otro, mediante la estrategia de la capitalización pública. Además, las dos versiones implican la "salvación de los recursos para inversión social que aporta la ETB", por un lado, mediante la obtención inmediata y cierta de los recursos por motivo de la venta, y, por el otro, mediante la inversión estratégica en la ETB para la obtención de recursos en el corto plazo, por concepto de utilidades, y en largo plazo bajo las condiciones de incertidumbre del mercado (Cuadro 7).

Por lo que se refiere a los argumentos que justificaron la decisión de "no vender", los más citados 
Cuadro 4 - Soluciones para la ETB

\begin{tabular}{|c|c|c|}
\hline Estrategia: Venta preventiva & $\begin{array}{l}\text { Estrategia: Fortalecimiento público-privado, } \\
\text { socio estratégico }\end{array}$ & Estrategia: Fortalecimiento público \\
\hline $\begin{array}{l}\text { Objetivos: evitar la quiebra de la empresa en } \\
\text { manos del Distrito; frenar la pérdida de valor; aislar } \\
\text { la empresa de presiones políticas; mejorar su gobierno } \\
\text { corporativo; garantizar su competitividad en el mercado } \\
\text { de telecomunicaciones gracias a la inversión privada. }\end{array}$ & $\begin{array}{l}\text { Objetivos: atraer socios estratégicos mediante } \\
\text { la cesión de control por parte del Distrito; garan- } \\
\text { tizar así el fortalecimiento de la empresa. }\end{array}$ & $\begin{array}{l}\text { Objetivos: fortalecer el patrimonio público distrital con } \\
\text { fórmulas diferentes a la venta o a la sesión de control que } \\
\text { garanticen la generación de utilidades y evite el monopolio en } \\
\text { el sector. }\end{array}$ \\
\hline $\begin{array}{l}\text { Opciones: } \\
\text { - Enajenación de la participación accionaria del } \\
50 \% \text { más una de las acciones del Distrito y } \\
\text { de las entidades descentralizadas y puesta } \\
\text { en venta primero al sector solidario y luego al } \\
\text { sector público. } \\
\text { - Enajenación de la participación accionaria del } \\
100 \% \text { de las acciones del Distrito y de las } \\
\text { entidades descentralizadas y puesta en venta. } \\
\text { - Vender es el mejor camino para atraer inverso- } \\
\text { res privados y fortalecerla mediante inyección } \\
\text { rápida de recursos. } \\
\text { - Fortalecerla ahora para venderla en mejores } \\
\text { condiciones. }\end{array}$ & $\begin{array}{l}\text { Opciones: } \\
\text { - Búsqueda de un socio estratégico privado } \\
\text { que asuma el control de la operación. } \\
\text { - Búsqueda de socio estratégico público o } \\
\text { privado que aporte tecnología, sin ceder el } \\
\text { control de la operación. } \\
\text { - Búsqueda de socio estratégico público o } \\
\text { privado que aporte capital, sin ceder el } \\
\text { control. }\end{array}$ & $\begin{array}{l}\text { Opciones: } \\
\text { - El Distrito puede aportar los recursos a mediano plazo si } \\
\text { capitaliza las utilidades que recibe de la ETB (\$100 mil } \\
\text { millones anuales, que entre } 1999 \text { y } 2010 \text { sumaron billón } \\
\text { y medio) y de la Empresa de Energía de Bogotá, de la } \\
\text { cual es propietario del } 89 \text { \% (\$200 mil millones anuales). } \\
\text { - La empresa puede endeudarse en el corto plazo y servir } \\
\text { los créditos con las utilidades que capitalizaría. Esta es } \\
\text { una opción respaldada por la calificación de Fitch Ratings } \\
\text { y Moodys Investor Services. } \\
\text { - Emisión de acciones y venta de activos improductivos } \\
\text { - Buscar alianzas estratégicas para el crecimiento en los cam- } \\
\text { pos más débiles de la empresa, tales como la prestación } \\
\text { del servicio de televisión y telefonía a larga distancia. } \\
\text { - Buscar alianzas estratégicas con empresas públicas de } \\
\text { Colombia y de otros países (como China, Corea e India). } \\
\text { - Realizar estudios rigurosos. }\end{array}$ \\
\hline $\begin{array}{l}\text { Promovieron: Gobierno nacional, Junta Directiva } \\
\text { ETB, línea editorial El Tiempo, expertos y algunos } \\
\text { concejales }\end{array}$ & $\begin{array}{l}\text { Promovieron: expertos, algunos concejales, } \\
\text { Contraloría de Bogotá }\end{array}$ & $\begin{array}{l}\text { Promovieron: exalcalde Jaime Castro, Alcaldía Mayor de } \\
\text { Bogotá, Contraloría de Bogotá, PDA, parte del Partido Liberal, } \\
\text { Senador Robledo (PDA), Sindicato, Red de Veedurías }\end{array}$ \\
\hline
\end{tabular}

Fuente: Elaboración propia, con base en la revisión de prensa (Anexos 1 y 2).

Cuadro 5 - Conjuntos categoriales del marco tecnológico

\begin{tabular}{ll}
\hline Mercado de telecomunicaciones & $\begin{array}{l}\text { Empresa patrimonio } \\
\text { público de la ciudad }\end{array}$ \\
\hline $\begin{array}{l}\text { competitividad } \\
\text { competencia }\end{array}$ & finanzas públicas \\
mercado de telecomunicaciones & patrimonio público \\
tecnología de telecomunicaciones & brecha e inclusión digital \\
servicios de telecomunicaciones & subsidios \\
grandes compañías & acceso a tecnologías \\
economías de escala & políticas públicas sociales \\
socio estratégico & inversión social \\
capitalización & debate público \\
indicadores financieros & conveniencia de la ciudad \\
generación de valor & alianzas públicas \\
innovación & \\
venta de servicios y paquetes digitales & \\
rentabilidad & \\
inversión privada & \\
\hline
\end{tabular}

por los concejales y la prensa fueron el "mal momento de la ETB" y la "coyuntura de crisis por la controversia en torno a la posible venta", factores que, en últimas facilitaron el consenso. Así, fueron expuestos los problemas y soluciones reseñados previamente y se hicieron cuestionamientos sobre la falta de claridad acerca del futuro de los 2,5 millones de usuarios, los 2000 trabajadores y el acceso subsidiado a Internet y telefonía fija de la población de los estratos socioeconómicos más bajos. Sin embargo, la decisión fue justificada ante la opinión pública en términos del "mal momento para vender", pues la crisis presionó condiciones de liquidación que bajarían el precio artificialmente y se incurría en mayor detrimento del patrimonio público.

Fuente: Elaboración propia, con base en revisión de prensa (Anexos 1 y 2). 
Cuadro 6 - Discursos en disputa

La ETB en el mercado de telecomunicaciones

La ETB es una sociedad comercial por acciones constituida como empresa de servicios públicos de carácter mixto, que opera en el mercado de las telecomunicaciones. Es autónoma e independiente, no está sometida al Régimen Legal Público, tiene el deber de competir con el sector privado en igualdad de condiciones, puede y debe tomar decisiones rápidas para adaptarse a las reglas del mercado

Tribunal Administrativo de Cundinamarca permite venta de ETB, en: El Tiempo, julio 12 de 2011), reconociendo que "no cuenta con la capacidad de inversión para proveer una oferta adecuada de servicios, tecnología, permanente innovación y desarrollo ni con la capacidad para realizar inversiones que le permita generar la oferta de productos requeridos por el mercado y competir de manera agresiva en el mercado de las telecomunicaciones" (Proyecto de Acuerdo 172 de 2011, Concejo de Bogotá)

\section{La ETB empresa patrimonio público de la ciudad}

La ETB es una empresa pública en el sector de las telecomunicaciones con participación minoritaria del sector privado.

Su función no consiste solo en generar rentabilidad, debe ser instrumento para proveer progreso, ayudar a reducir la brecha digital y generar utilidades que puedan seguir siendo invertidas en las políticas sociales del Distrito (salud y educación).

La ETB no está en riesgo, su venta no es una prioridad inmediata y venderla en la coyuntura actual implicaría venderla por debajo del costo de sus activos.

La empresa tiene las condiciones para ser proyectada en el sector de las telecomunicaciones para beneficio de la ciudad. (LOPEZ, 2011).

Fuente: Elaboración propia, con base en revisión de prensa (Anexos 1 y 2).

Cuadro 7 - Versiones del dilema

\section{ETB en el mercado de telecomunicaciones}

a) Vender la empresa para que los privados la salven y con los recursos obtenidos financiar programas sociales $\mathbf{o}$ b) financiar la empresa con recursos de otros sectores, perderla en el futuro mediato y perder los recursos públicos invertidos.

\section{ETB empresa patrimonio público de la ciudad}

a) Vender una empresa que genera ingresos pero que está en crisis y obtener recursos para inversión social en el corto plazo o b) invertir en la empresa e intentar maximizar el potencial de los recursos públicos en el mediano y largo plazo para salvar la empresa y mantenerla como fuente de recursos para inversión social.

Fuente: Elaboración propia, con base en revisión de prensa (Anexos 1 y 2).

\section{Consideraciones finales}

Es un avance importante que quince (15) años después de inaugurado el dilema "vender o no vender la ETB" la ciudad haya tenido un debate plural en torno a las opciones de futuro de esta infraestructura urbana sociotécnica. Es una pena que la memoria del debate siga dispersa en diferentes fuentes y que, ante la siguiente apertura de la controversia o la posible apuesta por una consulta popular para definir el futuro de la ETB, el ciclo de producción de los argumentos deba comenzar como si la ciudad nunca hubiese discutido lo mismo.

La productividad del ejercicio de debate realizado depende - además de la disposición a revelar los modelos de análisis y a discutir los dictámenes - de reconocer que el marco tecnológico de análisis que ha primado hasta ahora, sustentado en dos discursos que se rehúsan a generar encuentros, ha sido inútil tanto para resolver el dilema como para proponer y concretar salidas alternativas. Es preciso ampliar el marco y superar la polarización para observar dimensiones y posibilidades distintas. Un marco de carácter sociotécnico podría ser útil para llevar el debate más allá de los márgenes "mercado versus patrimonio público" que centran la atención en la ETB pero descuidan la interacción ETB-ciudad. Este marco permitiría abordar con determinación los diferentes aspectos de dicha interacción, tanto en la esfera del mercado como en la esfera pública; así como proponer un nuevo escenario para la toma de decisiones, ya acerca de la ETB sino acerca de respecto a la interacción ETB-ciudad.

La toma de decisiones respecto de la interacción ETB-ciudad requiere la vinculación sociotécnica de los diferentes actores que la producen, la usan y la soportan de forma individual y colectiva. Así, el análisis y la toma de decisiones no puede seguir siendo objeto de diálogo exclusivo entre actores del mercado y autoridades públicas. El cierre de la controversia "vender o no vender, versión 2011" dejó un panorama de alternativas promisorias para el 
fortalecimiento financiero y las alianzas tecnológicas, junto a un pobrísimo panorama de alternativas para la innovación tecnológica y sociotécnica que bien podría considerar la vinculación crítica de los usuarios y beneficiarios, las posibilidades de procesos colaborativos intersectoriales, la articulación con la planeación y la gestión urbanas, entre otros.

Como primer paso para presionar la ampliación del marco tecnológico es necesario promover las investigaciones en torno a las interacciones sociotécnicas ETB-ciudad, pues se requieren múltiples esfuerzos para trasladar a los actores a una arena distinta de discusión. La distinción entre las infraestructuras sociotécnicas urbanas y la ciudad como proceso sociotécnico resultante de la interacción de esas infraestructuras (Grahamm, 2001) ofrece claves de lectura pertinentes para proponer análisis de las interacciones de la ETB con otras infraestructuras de la ciudad, así como de los fenómenos sociotécnicos urbanos en la era de la información y la ciudad digital. Tales esfuerzos pueden contribuir para persuadir a los actores que han dominado el debate y a aquellos que han estado ausentes o en un segundo plano para asumir ese movimiento, pues los hábitos quinceañeros de debate no sucederán por espontánea tele-transportación.

Es urgente poner en consideración que, además de ampliar el marco tecnológico, es indispensable contar con un proyecto de ciudad que oriente de forma clara y estratégica la interacción con la ETB. Un proyecto que privilegie la "salvación de la ETB" desde la dimensión técnica en el mercado de las telecomunicaciones corre el riesgo de desatender los medios sociales con los que interactúa. Un proyecto que privilegie la "salvación de la ETB" desde la dimensión social corre el riesgo de desatender las complejidades técnicas y tecnológicas del mercado. Un proyecto que sintetice la dimensión técnica y social, sin que se enmarque en un proyecto de ciudad, desatenderá el soporte urbano en el que acontece esa interacción entre medios técnicos y sociales. Es el proyecto de ciudad el que puede orientar la reconfiguración de la disposición de los factores tecnológicos y sociales de la interacción ETB-ciudad y desarrollar sus potencialidades, de modo que el dilema alcance la mayoría de edad por el uso público y crítico de la razón en un marco claro de debate y no por el paso del tiempo.
No hay un único destino posible para la relación ETB-Ciudad porque no hay un orden lógico-racional de las cosas que determine su natural y exclusiva evolución en la esfera del mercado ni su natural estado de empresa pública intocable; hay argumentos razonables, escenarios posibles, condiciones de incertidumbre, modelos de análisis y propuestas decurrentes cuya exploración y deconstrucción crítica es tarea ya emprendida por investigadores y otros actores urbanos. Vender o no vender, esa no es la cuestión. La comprensión de las infraestructuras urbanas sociotécnicas y las decisiones estratégicas sobre su interacción con la ciudad requieren horizontes de análisis más amplios. En ese sentido, la deconstrucción de la controversia "vender o no vender la ETB, versión 2011”, la reflexión teórica propuesta y las posibilidades de investigación sugeridas en este texto pretenden ser un aporte.

\section{Referencias}

AIBAR, E. La vida social de las máquinas: orígenes, desarrollo y perspectivas actuales en el estudio social de la tecnología. Revista Española de Investigaciones Sociológicas, n. 76, p. 141-170, 1996.

AIBAR, E. Las culturas de Internet: la configuración sociotécnica de la red de redes. Revista Iberoamericana de Ciencia, Tecnología y Sociedad, v. 4, n. 11, p. 9-21, 2008.

AMIN, A.; THRIFT, N. Cities. Reimagining the Urban. Cambridge, Oxford: Polity Press, 2002.

BARDIN, L. Análise de conteúdo. São Paulo: Edições 70, 2011.

BARNES, B. Scientific knowledge and sociological theory. Londres: Routledge \& Kegan Paul, 1974.

BIJKER, W. E. La construcción social de la baquelita: hacia una teoría de la invención. En: GONZÁLEZ, M.; LÓPEZ, J. A.; LUJÁN, J. L. (Ed.). Ciencia, Tecnología y Sociedad. Barcelona: Ariel, 1997. p. 103-129.

BLOOR, D. Knowledge and social imagery. London: Routledge \& Kegan Paul, 1976.

BONILLA, J. I.; GARCÍA RAYA, M. E. Los discursos del conflicto: espacio público, paros cívicos y prensa en Colombia. Santa Fé de Bogotá: Pontificia Universidad Javeriana, 1998. 
CARNAP, R.; HANS, H.; NEURATH, O (Trad.). La concepción científica del mundo: el Círculo de Viena. Redes Revista de Estudios sobre la Ciencia y la Tecnología, Buenos Aires, n. 18, p. 103-149, 2002.

COLLINS, H. M.; PINCH, T. J. Frames of meaning: the social construction of extraordinary science. Londres: Routledge \& Kegan Paul, 1982.

FARÍAS, I. Ensamblajes urbanos: la TAR y el examen de la ciudad. Athenea Digital, Revista de Pensamiento e Investigación Social, v. 11, n. 1, p. 15-40, 2011.

GRAHAM, S.; MARVIN, S. Splintering urbanism: networked infrastructures, technological mobilities, and the urban condition. London: Routledge \& Kegan Paul, 2001.

JARAMILLO URIBE, J. Las ideas políticas en los años treintas. Revista de la Universidad Nacional, v. 3, n. 14-15, p. 25-29, 1987.

KUHN. T. S. La estructura de las revoluciones científicas. Buenos Aires: Fondo de Cultura Económica, 2004. (Título original: The structure of scientific revolutions. Chicago: University of Chicago Press, 1962).

LAMO DE ESPINOSA, E. El relativismo en sociología del conocimiento. Política y Sociedad, n. 14-15, p. 21-33, 1993.

LATOUR, B. Ciencia en acción. Como seguir a los científicos e ingenieros a través de la sociedad. Barcelona: Labor, 1992.

LATOUR, B.; HERMANT, E. Paris ville invisible. Paris: Les empêcheurs de penser en rond \& La Découverte, 1998.
LÓPEZ, C. Seamos responsables. El Tiempo. 14 jul. 2011. Disponible en: <http://www.eltiempo.com/archivo/documento/CMS-9906364>. Accesado en: 20 ago. 2011.

MERTON, R. K. La Sociología de la ciencia. Madrid: Alianza Editorial, 1977. (Tomo II).

MOUFFE, C. H. On the political. London, New York: Routledge \& Kegan Paul, 2005.

PÉREZ SEDEÑO, E. And the winner is... Algunas reflexiones que pueden llevar a una visión más ajustada de la ciencia. Éndoxa: Series Filosóficas, n. 12. p. 697-722, 2000.

PINCH, T. J.; BIJKER, W. E. The social construction of facts and artefacts: or how the sociology of science and the sociology of technology might benefit each other. Social Studies of Science, v. 14, n. 3, p. 399-441, 1984.

POPPER, K. La lógica de la investigación científica. Madrid: Tecnos, 1977. (Título original: Die Logikder Forschung.Vienna: Verlag von Julius Springer, 1935.)

POPPER, K. Realismo y el objetivo de la Ciencia: Post Scriptum a. Madrid: Tecnos, 1985. v. II.

VALDERRAMA, A. Teoría y crítica de la construcción social de la tecnología. Revista Colombiana de Sociología, n. 23, p. 217-233, 2004.

Recibido: $14 / 03 / 2012$

Recebido: 14/03/2012

Received: 03/14/2012

Aprobado: 03/10/2012

Aprovado: 03/10/2012

Approved: 10/03/2012 